\title{
The Impact of In-Service Training on Computer Application Educators: Challenges Experienced and Skills Acquired
}

\author{
Jennifer K Bihi \\ Faculty of Humanities, Central University of Technology, \\ Free State, Bloemfontein, South Africa \\ jbihi@cut.ac.za \\ *Jacob M Selesho \\ Faculty of Management Sciences, Vaal University of Technology, \\ Vanderbijpark, South Africa \\ jacobs@vut.ac.za
}

\section{Doi:10.5901/mjss.2014.v5n7p411}

\begin{abstract}
It is generally believed that Information Communication Technologies through the use of Computer Applications Technology can extend knowledge and education to poor and marginalised people in South Africa. However, African countries still face many challenges in trying to provide appropriate and sustainable solutions for improving education and skills that will support the development of educators in all communities; this can be viewed in light of the millennium developmental goal. Thus the Department of Education put measures in place to bridge the gap in knowledge, skills and understanding of Computer Application Technology (CAT) educators through the provision of in-service training (INSET) programs. The research study was aimed at investigating challenges that CAT educators were experiencing in their classrooms in Secondary Schools in the Free State province. The study made use of a survey and an evaluation research design. The target population for this study was all Further Education and Training (FET) Phase educators in all secondary schools in the Free State Province. A selfconstructed questionnaire was used to collect qualitative data. The study revealed that the INSET program still needs to improve on its content relevance to syllabus and it should provide educators with skills in dealing with the challenge of teaching learners with disabilities. The majority of educators were satisfied with the INSET program as they indicated that it assisted in enhancing their skills and content knowledge; they further indicated that it gave them motivation to go into classrooms and teach. That the study did achieve its goal which was to assess the impact of INSET programs for CAT educators in the Motheo District, Free State province.
\end{abstract}

Keywords: Computer Application. Impact. Challenges. Experiences. Educators.

\section{Introduction}

The National Curriculum Statement (NCS), and recently, the newly introduced Curriculum Assessment and Policy Statement (CAPS), visualise educators who are qualified, competent, dedicated, caring, and have the ability to fulfil the various roles, which included being mediators of learning, interpreters and designers of learning programmes and materials, leaders, administrators and manager, scholars, researchers and lifelong learners, community members, citizens and pastors, assessors and subject specialists (Parker; 2011: 2). These are the seven most important roles set by the Department of Education (DoE); these endeavours cannot be met if the DoE does not focus on its employees in the system that are regarded as the key to effect improvement of the quality in schools. However, some practising educators view their own ongoing professional development as a huge challenge (Gulston; 2010: 1)

\section{Curriculum Changes and Computer Application Technology}

Changes in the curriculum delivery impacted seriously on the training afforded to CAT educators with regard to the implementation of the NCS, and recently, the newly introduced CAPS. However, Munonde (2007: 31) emphasises that "the nature and extent of policy-making for initial and continuing professional educator development varied from country to country". All educators are key contributors to the transformation of education in South Africa. The NCS (grade 10 to 12 general), together with the norms and standards for educators, visualised educators who were qualified, competent, 
dedicated, caring and had the ability to fulfil the various roles. These roles included being mediators of learning, interpreters and designers of learning programme and materials, leaders, administrators and managers, scholars, researchers and lifelong learners, community members, citizens and pastors, assessors and subject specialists (Parker; 2011: 2). Therefore, the researcher sought to undertake an evaluation of the training provided to educators towards improving the quality of teaching and learning in CAT at secondary schools of the Motheo district, Free State Province.

\section{Needs and Importance of In-Service Training Programme for Educator Education}

INSET is any vocational training acquired during employment, and an undertaking to engage in such training is usually part of the appointment agreement between employer and employee. In the current situation in South African education, training is necessary to re-orientate educators to new goals and values, to prepare them to cope with curriculum changes, to train them in new teaching and learning method, and to provide them with the knowledge and skills to teach new learning areas (Conco; 2004: 04). INSET also assists newly qualified educators, as they are frequently criticised for being under-prepared in the content knowledge of the subjects/learning areas they teach. Perhaps the set standard that they should maintain of learner-centred education has contributed to the under-emphasis on content knowledge, and the ability to make it accessible to learners. Nonetheless, whatever the reason, it is clear that no one can teach something they themselves do not know, and a re-emphasis on the key importance of content knowledge is needed at this time. Learner centeredness means that the learners are active participants in the learning process (Pillay; 2002: 222). The content knowledge that is needed by educators to improve their teaching can only be acquired through the attendance of INSET programmes.

The study emanates from the premise of the Teacher Development Summit (2009), which was to facilitate effective system-wide educator development that would lead to sustainable improvement in the quality of teaching and learning in school classrooms.

The evaluation was undertaken against a background and context of economic empowerment opportunities that emerged with the post-1994 democratic order in South Africa. The imperative to transform South African society stems from the need to address the imbalances of the past, specifically in the field of CAT (Department of Education; 2008: 9). The importance of this study was to ensure that the skills development programme offered to educators addresses the quality of teaching and learning of CAT as a learning area, and develops them to be able to change the learning process and implement it according to the requirements of the DoE. This will then assist in the improvement of quality education, and ensure that educators benefit, to their fullest potential, from training programmes offered to them. This will in turn assist Inset programmes as they will have information which informs them regarding any weaknesses, strengths, and also about educator needs for future developmental opportunities (Uysal; 2012: 14).

The NCS required that the knowledge and skill levels of educators be diverse, to deal with the vastly refined and more thought-provoking curriculum matters. Despite the history of achieving marginal benefits from using technology in education, many schools were investing heavily in CAT (Prince; 2007: 8). In some schools, the DoE was of the view that by encouraging more learners to enrol for CAT will results in a change in society for the better, as they will have employment opportunities (Prince; 2007: 8). While the DoE was on the drive to increase the enrolment rate in CAT, it was also important to take stock of the competence level of the educators tasked with the responsibility of teaching CAT. The majority of the educators were trained prior 2005; therefore, while introducing the curriculum reform, the DoE, in most cases, followed the route of educator development programmes in the form of INSET. They did this by aligning their training with the educator development framework, which stated that all educators needed to enhance their skills, not necessarily their qualifications, for the delivery of the new curriculum. A large majority need to strengthen their (CAT) subject knowledge base, pedagogical content knowledge and teaching skills (DoE; 2007: 16). In the Free State Province, educators would attend this programme during the school vacation or on weekend block sessions. These programmes were subject/content related for a particular grade, where the emphasis was on the content mastery.

Conco (2005: 3) states that at the centre of any successful school improvement plan or reform initiatives are the people who translate goals into reality. In a school, educators are the key implementers of new programmes and practice that impact on learning. Although a well-crafted mission statement, specific improvement goals, milestones and a timeline are important, a school improvement plan must include a strategy to address educator development. He further states that educators will not naturally acclimatise to a new set of goals and expectations; nor should they be left to "speed up" on their own, thus a proactive approach to educator development is required. Therefore, the researcher felt there was the need to assess the impact of CAT INSET programmes, offered to the CAT educators, on the quality of teaching in CAT lessons.

On the basis of the situation set out above, the research question is formulated and the research problem 
addressed by the study is the impact of assessment of training programmes offered to CAT educators in secondary schools in the Free State Province.

The main aim of this study was to assess what were the challenges experienced by educators in implementing CAT in classrooms?

Sampling refers to a technique employed to select a small group (the sample) with a view of determining characteristics of a large group (Sebastiao; 2009: 28). Babbie (2010: 138) defines sampling as a set of individuals selected from a population to represent the population in a research study. The sampling technique used by the researcher was purposive sampling, as it allows researchers to choose their sample based on whom they think could be appropriate for the study. This is used primarily when there are a limited number of people that have the expertise in the area being researched (Adler \& Clark; 2011: 123). The population for this study was all educators teaching CAT in Free State Province, which include Motheo District, Thabo Mofutsanyana District, Lejeleputswa District, Fezile Dabi District and Xhariep District. The choice of the province was based on the fact that selected subjects were challenged in terms of the provincial resource retention strategies in schools, stealing of computers, and maintenance, to a large degree. The sample that was chosen was CAT educators at secondary schools in the Motheo District, Free State Province.

\section{Research Design and Method}

According to Imenda and Muyangwa (2006: 25) research design is defined as the basic plan of a study, therefore, the term refers to how the study was intended to be carried out. For this study, the researcher used evaluation research, which Imenda and Muyangwa (2006: 32) define as research that involves the systematic collection of information on the worth of programmes, products and techniques, and then using the information to make judgements. Imenda and Muyangwa (2006: 32) state that there are three kinds of evaluation research; need assessment, evaluation of new programmes during the development process, and evaluation of completed programmes of study. For this study, the researcher focused on the completed programmes of study.

The researcher used both the qualitative and quantitative research approaches for this study. The reason for using both approaches was that the survey method was used and the questionnaire that was constructed to gather information from participants consisted of both open- and closed-ended questions. According to Trochim (2006: 38), a qualitative approach is a general way of thinking about conducting qualitative research. It describes, either explicitly or implicitly, the purpose of the qualitative research, the role of the researcher, the stages of research, and the method of data analysis. The purpose of using this qualitative research is clearly interpreted by Imenda and Muyangwa (2006: 92) as, "it seeks to give description of situations and events as they appear or occur without manipulation by the researcher".

In quantitative studies, the mass of data does not shape and limit the analyses, for example, if you collect data based on simple interval-level quantitative measure, the analyses are likely to be fairly delimited (descriptive statistics, correlation, regression or multivariate models are used). Generalisation in the quantitative mode also tends to be fairly straightforward because some aggregate statistics such as a mean or median are computed from the same variable collected from everyone in the sample. Ultimately, quantitative research reaches generalisation based on statistical projections (Conco; 2004: 27). According to Selesho (2008: 95), quantitative research is based on the collection and analysis of numerical data, usually obtained from questionnaires, tests, checklists and other formal paper-and-pencil instruments. In this regard, quantitative research entails more than just the use of numerical data, as it involves maintaining control over contextual factors that might interfere with the data to be collected.

\section{Data Collection}

Data were collected by means of a self-constructed questionnaire to answer the research questions of the study. A questionnaire was prepared and provided to all CAT educators who attended an open workshop for CAT Educators at one High School in the Free State Province. The questionnaire consisted of open-ended and closed response questions.

The researcher favoured the use of questionnaires as one of the data collection instruments, as it offers an objective means of collecting information about people's knowledge, beliefs, attitudes and behaviour (Rabie; 2007: 112). Webster (2008: 1) declares that a questionnaire that is appropriately structured and reliably administered becomes a fundamental instrument by which statements can be made about specific groups, or people, or an entire population. The use of a questionnaire was selected as it is relatively economical and is easy to obtain information from participants in a short period of time. The questionnaire was distributed to CAT educators to gather information relating to the research questions at a workshop, which was organised for CAT educators, at one High School in the Free State

In analysing data for the current study, the researcher collected data through the use of the questionnaires 
(Appendix B). The closed-ended questionnaires were seen as suitable instruments to be used in collecting data among the educators. The study only focused on the educator development of CAT, although there were many issues emanating from the respondents and their colleagues.

In view of the envisaged focus, a framework was designed on how to record the data of both self-evaluations compiled by the schools as well as the reviewers reports. A process of analysing data was followed by firstly, identifying particular patterns and themes that outline and address the three main aspects of the conclusion(s) thereof. A comparison was made between the similar information gathered in both reports, and points of major similarity were identified by reviewers.

\section{Discussion of Findings}

A discussion on findings from the research questions is presented below as categories in the questionnaire.

\subsection{Category 1}

In this category, questions were based on personal information of participants and the following was deducted regarding the age of participants. The data in this question of age indicated that 42 percent of educators ranged between the ages of 20-30 years. This means that this statement is in line with a study by Westerman and Davies (2000: 478) who states that young people generally have been provided with greater opportunities and incentives to develop skills than have their older counterparts (see Chapter 2). In the question of teaching experience, the researcher wanted to find out if teaching experience played a vital role in the teaching of CAT. The data in this research question indicated that 55 percent of educators had teaching experience of 1-5 years. The findings reveal that the majority of educators have less than 5 years' experience, meaning that they might still need to enhance their skills in teaching. Educators' responses with regard to experience with computers indicated that 47,5 percent had 6-10 years' experience. The findings in this question indicated that the majority of educators had computer experience. This means that they are in a better position to mentor or assist future educators since they should suggest approaches for using ICT in actual classroom situations.

The data on the total number of training sessions that educators attended indicated that 55 percent attended training sessions, whilst some educators have attended more than 11 training sessions. The finding that is being deducted on this question is that the majority of educators might not have attended all training sessions, which were offered. This leads to educators being neither sufficiently prepared nor adequately confident to carry out full integration of ICT in their classroom. Furthermore, 95 percent indicated that they had used computers prior to attending training sessions. The findings in this question indicated that the majority of educators teaching CAT have access to computers, which means that they had some prior knowledge on use before attending their training sessions. 97,5 percent also indicated that they used computers at home. The finding on this question indicated high levels of computer use at home and at work, which improved the quality of current practices through better preparation and student testing.

\subsection{Category 2}

The data on the question of the level of computer use indicated that all (100 percent) educators in the study rated their level of computer use as good. This indicates that the training programme facilitators do not necessarily have to focus on the basic computer skills when planning their training sessions, and it also implies that educators have a better knowledge and understanding of the tool that they use in their respective classrooms. All (100 percent) educators also indicated that their measurement of confidence regarding computer use was good; this finding differs with the one of the educator level barriers that indicates that confidence is one of the barriers that prevents educators from using ICT in their teaching. Furthermore, 95,5 percent indicated that they have a good level of computer use. This finding indicates that these educators will have no problem in transferring learning to their learners, which will influence learner achievement.

Educators were also requested to respond on their level of integration (theory is put into practice by means of software and hardware) of computers in classroom. Their data indicated that 85 percent of educators felt that their level of integration with computers in their classroom was good. From the findings provided, it is evident that the majority of educators do integrate computers in their classroom, which differs with the study by Bingimlas (2009: 238), which indicates that educators lacked the knowledge and skills to use computers and were not enthusiastic about the changes and integration of supplementary learning associated with bringing computers into teaching practices. The data on level of interest in using the computer indicated 95 percent response rate from educators revealing that they had a good level of interest in using computers. Meaning that the majority of educators were able to learn alongside their learners, and in 
doing so, they maintained a passion for their subject.

\section{Conclusions}

The conclusions for this study are discussed according to the research question of the study.

- To identify challenges experienced by educators in facilitating CAT in their classrooms

The following challenging areas were identified by educators who attended INSET programmes:

They indicated that their training content was not relevant to the syllabus and that the duration of the training programme must be extended as they felt that there was a need to attend more sessions in order to equip them with the necessary knowledge and skills.

Thus, it can be concluded that this study answered the research questions, which were posed by the researcher. Furthermore, the study achieved its goal in assessing the impact of INSET programmes for CAT educators in the Motheo district, Free State Province, and it reveals that the programme still needs to improve on its content and relevance to the syllabus and provide educators with skills in dealing with learners who have disabilities.

\section{References}

Adler, E.S., and Clark, R. 2011. An invitation to social research: How it's done. Cengage Learning.

Babbie, E. R. 2010. The practice of social research. Wadsworth Cengage learning

Bingimlas, K. A. 2009. Barriers to the successful integration of Information Communication Technology in teaching and learning environments: A review of the literature. RMIT University. Bandoora. Eurasia Journal of Mathematics, Science and Technology Education, 5(3): 235-245.

Conco, Z. P. 2005. "How effective is in-service training for educators in rural schools". Unpublished M.Phil in education thesis. University of Pretoria.

Department of Education. 2007. National Policy Framework for teacher education and development in South Africa-Thutong SA Educational portal. Pretoria.

Department of Education. 2008. Learning Program Guideline, Grade 10-12 (Information and Communication Technology). Pretoria.

Fambaza, T. 2012. The experiences of teachers in teaching Computer Application Technology at Further Education and training band. MEd. University of Kwazulu-Natal.

Imenda, S. N., and Muyangwa, M. M. 2006. Introduction to Research in Education and Behavioural Sciences. Tshwane University of Technology Publishers, Pretoria.

Manuel, T. 2011. National Planning Commission on implications of the national development plan for the public service. Conference of the senior management service. CSIR conference centre.

Munonde, L. C. 2007. Effective teaching and learning in secondary schools of the Thohoyandou district through continuous professional development programs. Unpublished Master's Thesis. University of South Africa.

Osunde, A.U. and Omoruyi, F.E.O.2004. An evaluation of the National Educators Institutes Manpower Training program for teaching personnel in Mid-Western Nigeria. International Education Journal, 5 (3):405-409.

Parker, D. 2011. Official pedagogic identities from South African Policy-some implications for mathematics teacher education practice. Pythagoras, 63 (2): 2-17.

Pillay S. 2009. Science teacher educators: A shift towards student-centredness. Episteme-3 International conference to review research in science, technology and mathematics education. Mumbai. India. January 5-9.

Prince, G. L. 2007. Implementation of computers in schools: A case study of five schools in the Makana and Somerset East districts. Unpublished Master's Thesis. Rhodes University.

Rabie, S. 2007. Medical student's perceptions of the utility of concept mapping. ProQuest.

Sebastiao, M. M. 2009. An investigation into the causes of Mozambican teenage migration into South Africa. Unpublished B. Tech Degree Thesis. Cape Peninsula University of Technology.

Selesho, J. M. 2008. Quality Assurance Mechanisms in Selected Universities of Technology following the sertec experience. Unpublished D-Tech thesis. Tshwane University of Technology.

Trochim, W. M. K. 2006. Research Methods Knowledge base. Web Centre for social research methods. www.socialresearchmethods.net.

Uysal, H. H. 2012. Evaluation of an In-service Training program for Primary-school language teachers in Turkey. Australian Journal of Teacher Education. 37 (7): 7-15.

Westerman, S. J. and Davies, D. R. 2000. IN-DEPTH REVIEW: Acquisition and application of new technology skills: The influence of age. Great Britain. Oxford Journals, 50 (7): 478-482.

www.merriam-webster.com/dictionary/questionnaire (accessed 18/01/2013) 